\title{
Shrouded CMC Rotor Blades for High Pressure Turbine Applications
}

\section{GT2018-76827}

\author{
Robert J. Boyle \\ N\&R Engineering \\ Parma Heights, $\mathrm{OH}$ \\ rbrjboyle760@gmail.com
}

Lucas M. Agricola

The Ohio State University

Columbus, $\mathrm{OH}$

agricola.6@buckyeyemail.osu.edu

\author{
Ankur H. Parikh \\ N\&R Engineering \\ Parma Heights, $\mathrm{OH}$ \\ aparikh@nrengineering.com
}

\author{
Ali A. Ameri \\ The Ohio State University \\ Columbus, $\mathrm{OH}$ \\ ameri.1@osu.edu
}

\author{
Vinod K. Nagpal \\ N\&R Engineering and Management Services \\ Parma Heights, $\mathrm{OH}$ \\ vnagpal@nrengineerin.com
}

\begin{abstract}
The density of Ceramic Matrix Composite $(C M C)$ materials is approximately $1 / 3$ the density of metals currently used for High Pressure Turbine(HPT) blades. A lower density, and consequently lower centrifugal stresses, increases the feasibility of shrouding HPT blades. Shrouding HPT blades improves aerodynamic efficiency, especially for low aspect ratio turbine blades. This paper explores aerodynamic and structural issues associated with shrouding HPT rotor blades. Detailed NavierStokes analysis of a rotor blade showed that shrouding improved blade row aerodynamic efficiency by $1.3 \%$, when the clearance was $2 \%$ of the blade span. Recessed casings were used. Without a shroud the depth of the recess equaled the clearance. With a shroud the recess depth increased by the shroud thickness, which included a knife seal. There was good agreement between the predicted stage efficiency for the unshrouded blades and the experimentally measured efficiency. Structural analysis showed a strong interaction between stresses in the shroud and peak stresses at the hub of the blade. A thin shroud of uniform thickness only moderately increased maximum blade stress, but there were very high stresses in the shroud itself. Increasing shroud thickness reduced stresses in the shroud, but increased blade stresses near the hub. A single knife seal added to the thin shroud noticeably decreased maximum shroud stress, without increasing maximum blade stress. Maximum stresses due to pressure loads and combined pressure and centrifugal loads were nearly the same as the maximum stresses for individual pressure or centrifugal loads. Stresses due to a $100 K$ temperature
\end{abstract}

difference across the blade walls were much lower than centrifugal or pressure load stresses.

$\begin{array}{lll} & & \text { Nomenclature } \\ S^{\prime \prime \prime} & - & \text { Rate of entropy generation } \\ & & \text { per unit volume, } \mathrm{W} / \mathrm{m}^{3}-K \\ T & - & \text { Temperature, } K \\ u_{i} & - & \text { Velocity component, } \mathrm{m} / \mathrm{sec} \\ x_{i} & - & \text { Coordinate direction, } \mathrm{m} \\ y_{1}^{+} & - & \text {Dimensionless first grid line } \\ & - & \text { distance from solid surface } \\ \mu_{\mathrm{EFF}} & - & \text { Effective viscosity, } P a-s e c\end{array}$

\section{INTRODUCTION}

This paper addresses the feasibility of shrouding Ceramic Matrix Composite(CMC) blades for use in the High Pressure Turbine(HPT). Shrouding is feasible for CMC blades of the HPT, while shrouding is less common for current metallic HPT blades. Centrifugal stresses are proportional to material density, and CMCs are only one third as dense as single crystal superalloy blade materials. Shrouding reduces clearance loss, and the stage efficiency benefit from shrouding HPT rotor blades increases as the blade clearance-to-span ratio increases. At constant thrust increasing engine Overall Pressure Ratio(OPR) yields smaller HPT cores, which is likely 
to increase clearance-to-span ratios. Clearance loss is a major loss for unshrouded HPT rotor blades, and shrouding the blades is expected to reduce the clearance loss by a third to a half(Yoon et al.(1)). Even though lower centrifugal stresses are expected when CMC blades are used, a CMC rotor blade needs sufficient strength to accommodate centrifugal, pressure, and thermal load stresses. Some $\mathrm{SiC} / \mathrm{SiC} \mathrm{CMC}$ materials have strengths in the fiber directions close to the strengths of advanced metal alloys, even when the $\mathrm{CMC}$ is at a higher temperature.

Detailed steady state Navier-Stokes calculations were used to compare blade row aerodynamic efficiency for shrouded and unshrouded blades. A recessed casing was included in the analysis of the unshrouded and shrouded blades. The shrouded blade had a knife seal to reduce through flows in the clearance region.

Stress analyses were done for shrouded and unshrouded HPT blades. Different shroud configurations were examined. Stresses were calculated for centrifugal and pressure loads applied separately, and when these loads were applied simultaneously. Thermal stresses were calculated for a uniform temperature difference across the blade walls. The unshrouded HPT blade described by Moffitt et al.(2) is used for both aerodynamic and stress analyses. This reference gives blade coordinates, and experimental aerodynamic performance for an unshrouded blade.

\section{REFERENCE TURBINE BLADE}

A turbine, described and tested by Moffitt et al.(2), was analyzed. This turbine was for a HPT application, and was unshrouded. The turbine was described as having relatively thick leading and trailing edges, and a high maximum thickness-to-chord ratio, along with a low aspect ratio. These characteristics make this design a suitable reference case for investigating the benefits of CMC turbine blades. The rotor blade axial chord was $3.43 \mathrm{~cm}(1.35 \mathrm{in}$.$) ;$ the span was $3.81 \mathrm{~cm}(1.5 \mathrm{in}$.); and the tip radius was $25.4 \mathrm{~cm}(10 \mathrm{in}$.

The aerodynamic analysis assumed a recessed casing over the blade. For the unshrouded blade the recess height and the clearance were both $2 \%$ of span. When the shroud was added the casing recess was significantly greater. The shroud had a knife seal to retard clearance region axial flows. The clearance above the knife seal remained at $2 \%$ of the span. A $2 \%$ clearance was chosen primarily to give a significant efficiency change due to shrouding the rotor. However, the absolute value of this clearance, $0.076 \mathrm{~cm}(0.030 \mathrm{in}$.), is appropriate for future HPT turbines, with their lower volumetric flow rates. A notional $\mathrm{N}+3$ single aisle aircraft engine has a HPT span only half the span of the analyzed turbine.(Jones(3)). A $2 \%$ clearance in the notional engine corresponds to an absolute clearance of $0.038 \mathrm{~cm}(0.015 \mathrm{in}$.$) .$

Figure 1 shows three sections of the blade given by Moffitt et al.(2). The blade shape varies nearly linearly from hub to tip. The design mean inlet and exit flow angles were $50^{\circ}$ and $59^{\circ}$.

Figure 2 shows the tip region of the blade with a shroud. This geometry was used for the aerodynamic analysis. The blade geometry was provided by Moffitt et al.(2), and the shroud geometry is similar to the shroud discussed by Kanjirakkad et al.(4). For both geometries the casing recess extended $3.8 \mathrm{~mm}$, or $11 \%$ of the axial chord in front of and behind the blade. The shroud thickness and the actual clearance were $2 \%$ of the span. The knife seal was $4.05 \mathrm{~mm}$, or $10.6 \%$, of the span. The casing recess was $5.56 \mathrm{~mm}$, or $14.6 \%$ of the span. The undersurface of the shroud and the tip of the unshrouded blade were flush with the upstream stator tip location.

\section{RESULTS}

Both aerodynamic and stress analysis results are presented, each in their own section. The aerodynamic results focus on the efficiency gain from shrouding the HPT rotor blade. The stress analysis results focus on the distribution of stresses when a shroud is added. This is done for centrifugal, pressure, and thermal loads.

\section{Improved Efficiency for Shrouded Rotors}

A 3D steady state analysis was done for the shrouded and unshrouded rotor blade geometries using the Star-CCM+ computer code. The $k-\omega$ SST turbulence model was used. This code is appropriate for turbomachinery analysis. For example, Lin et al.(5) used the Star-CCM+ analysis for the conjugate analysis of heat transfer to a gas turbine vane. The $k-\omega$ SST turbulence model was used by by Ameri et al.(6) to predict turbine blade tip region clearance flows and heat transfer. For the results presented herein wall functions were not used because the near wall dimensionless wall distance, $y_{1}^{+}$, was sufficiently low.

Navier-Stokes analyses were done for the shrouded and unshrouded rotor blade. The first objective of the aerodynamic analyses was to determine the increase in blade row efficiency due to shrouding a HPT blade. The second objective was to show that the CFD analysis agreed reasonably well with experimental stage efficiency data for the unshrouded rotor blade. 


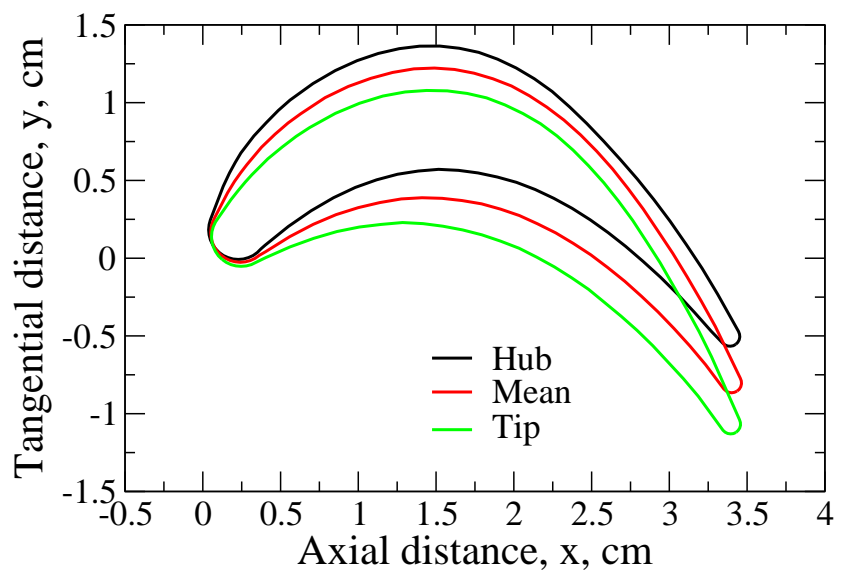

Figure 1. THREE SECTIONS of the HPT BLADE (MOFFITT et al.(2)).

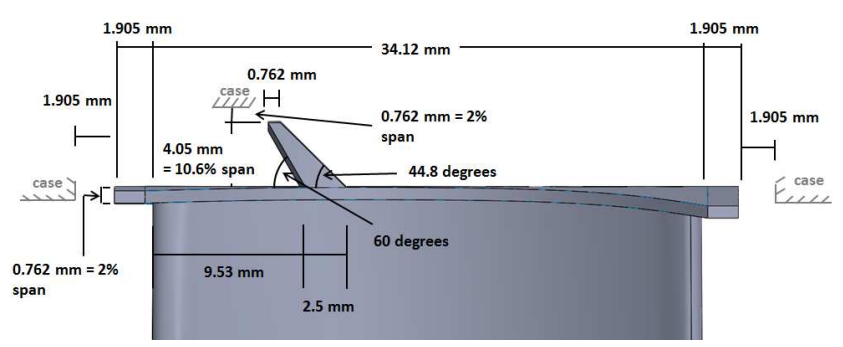

Figure 2. BLADE TIP REGION.

Even with only a single knife seal the calculated efficiency increased by $1.3 \%$, for a $2 \%$ clearance. The analysis agreed reasonably well with the experimental unshrouded turbine after accounting for differences in clearance and casing geometry. The measured stage efficiency was $88.6 \%$ for a design clearance of $0.8 \%$. Moffitt et al.(2) estimated the sensitivity of efficiency to clearance, and at $2 \%$ clearance the stage efficiency was estimated to be between $86.4 \%$ and $87.0 \%$. The calculated efficiency was $87.7 \%$ and included a $2 \%$ absolute total pressure drop across the stator. The calculated efficiency is $0.7 \%$ to $1.3 \%$ higher than the estimated experimental efficiency at $2 \%$ clearance. A likely reason for the remaining efficiency over prediction is that the analysis was for a recessed casing, but there was no recess in the experimental test. The recess provided geometric commonality with the shrouded rotor configuration. Haas and Kofskey(7) showed that recessing the casing contributes to lower sensitivity of stage efficiency to clearance. It is expected that for no casing recess the calculated efficiency would be lower than $87.7 \%$, and closer to the clearance corrected experimental efficiency of $87 \%$ or less.

Figure 3 shows views of grids used. Polygon grids were used away from solid surfaces. Body fitted grids were used near solid surfaces. This can be seen in the view showing the trailing edge region. The near wall spacing was $1.5 \times 10^{-7} \mathrm{~m}$, which was sufficient to give an average $y^{+}$near 0.6 for both
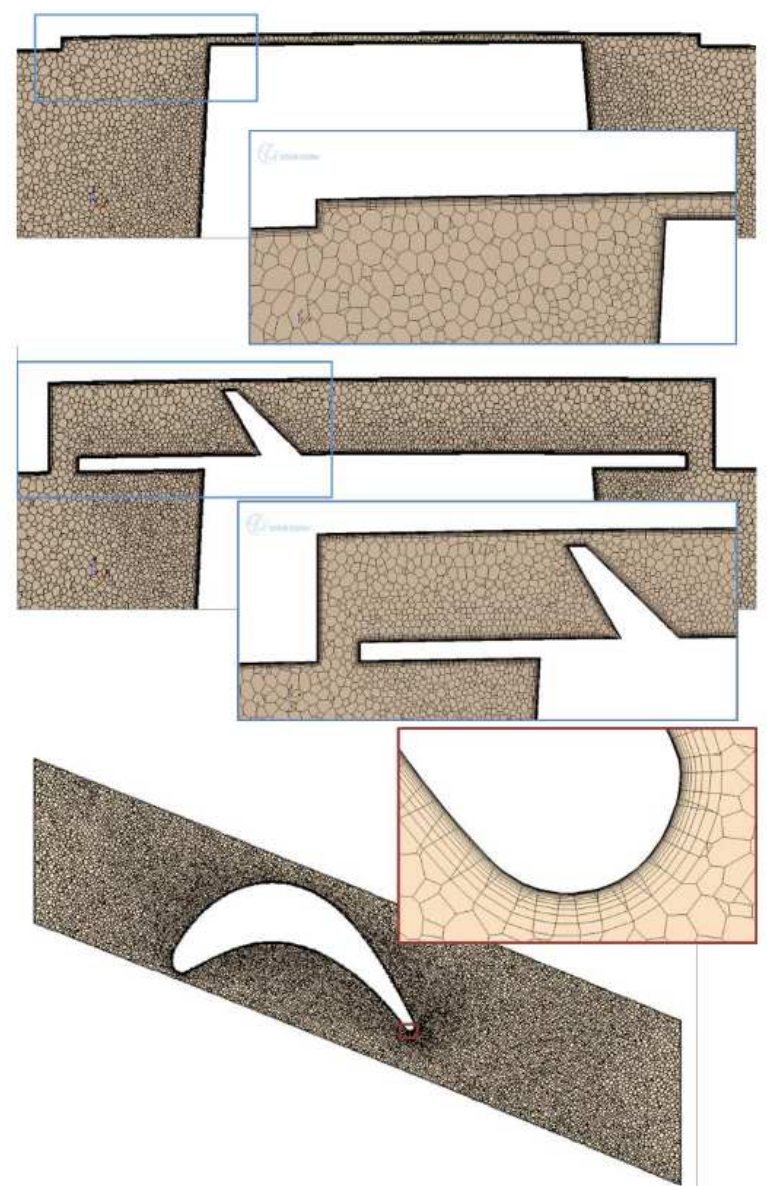

Figure 3. GRIDS USED for AERODYNAMIC ANALYSIS.

the shrouded and unshrouded cases. The cell count for the unshrouded case was 3.39 million. For the shrouded case the cell count increased by $25 \%$ to accommodate the increased clearance volume.

Figure 4 shows midspan local static pressures normalized by the midspan inlet relative total pressure for both shrouded and unshrouded rotor blades. The midspan pressure distributions are nearly identical. This is not surprising. Even for relatively low aspect ratio blades, the effects on pressure distributions from clearance flows are seldom seen near midspan. The minimum pressure ratio on the suction surface corresponds to an isentropic Mach number greater than one. Reference 2 gave the design intent velocity diagrams. The midspan exit relative Mach number was 1.07. The experimental exit relative Mach number was slightly higher. The local minimum pressure near the front of the pressure surface is the result of a high inlet velocity.

Figure 5 compares tip region viscous entropy generation per unit of volume for unshrouded and shrouded cases. This quantity, $S^{\prime \prime \prime}$, is calculated from local values of temperature, effective viscosity, and velocity gradients. It is given by:

$$
S^{\prime \prime \prime}=\frac{2 \mu_{\mathrm{EFF}}}{T}\left(\epsilon_{i j} \epsilon_{i j}-\frac{1}{3}(\nabla \cdot \vec{u})^{2}\right)
$$




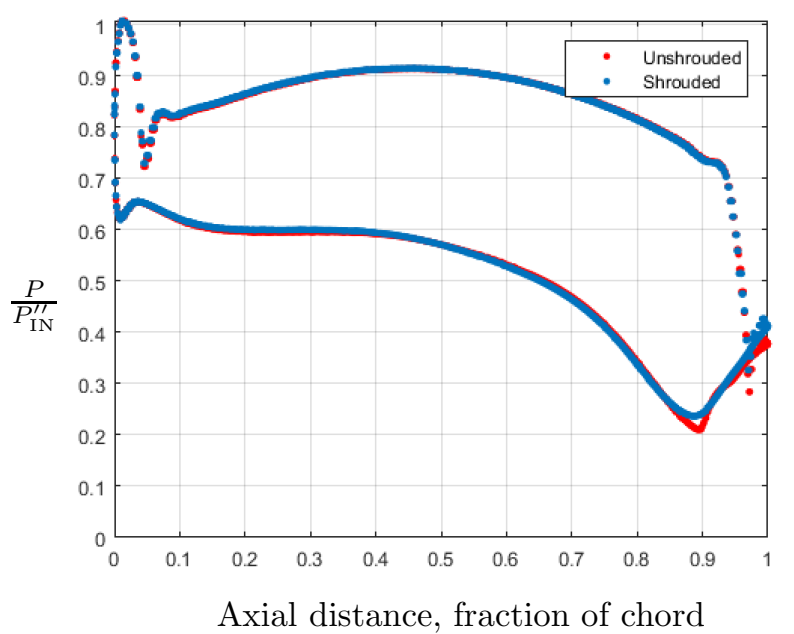

Figure 4. MIDSPAN SURFACE PRESSURES, UNSHROUDED \& SHROUDED BLADES.

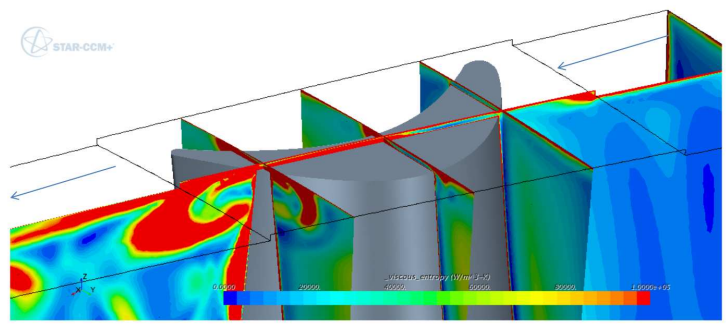

a) Unshrouded rotor

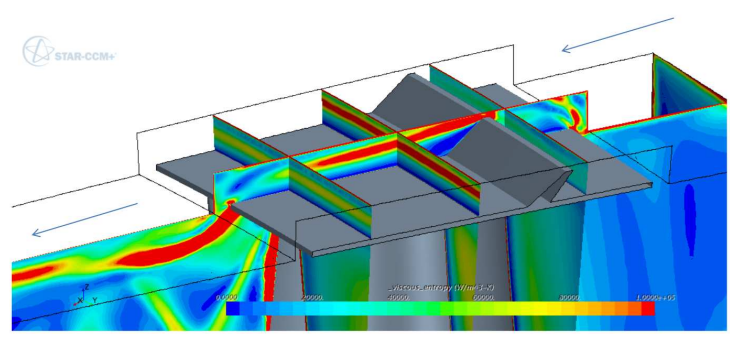

b) Shrouded rotor

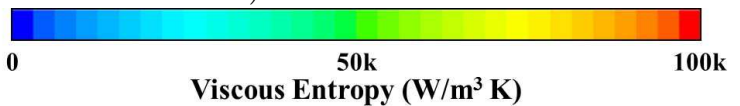

Figure 5. VISCOUS ENTROPY, $W / m^{3}-K$.

where:

$$
\epsilon_{i j}=\frac{1}{2}\left(\frac{\partial u_{i}}{\partial x_{j}}+\frac{\partial u_{j}}{\partial x_{i}}\right)
$$

Red regions of high viscous entropy correspond to regions of high loss. Tip region results are shown on an axial-radial plane midway through the computational domain, and on three tangential-radial planes. Over the blade the region of high viscous entropy for the unshrouded case appears smaller than for the shrouded case. But, this is an illusion. For both cases the gap is only $2 \%$ of the span. The knife seal increases the distance between the shroud and

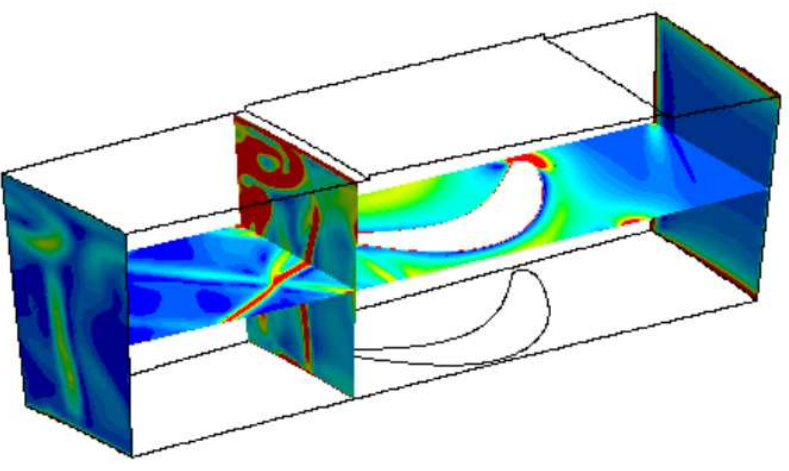

a) Unshrouded rotor

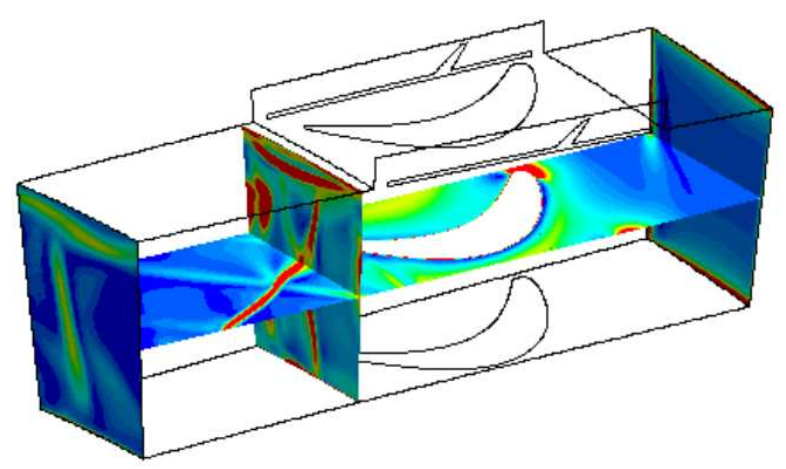

b) Shrouded rotor

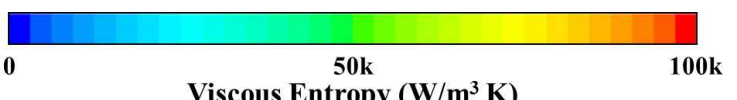

Figure 6. VISCOUS ENTROPY in MIDSPAN PLANE.

casing. There is a high loss region starting near the same location as the minimum suction surface pressure seen in Fig. 4. In the unshrouded case, (Fig. $5 \mathrm{a})$, the region of high loss is larger than the loss region for the shrouded case, (Fig. 5b). At this suction surface location the high loss region extends down the span, and is larger for the unshrouded case.

Figure 6 shows viscous entropy generation in a midspan plane for both the shrouded and unshrouded cases. There are inlet and exit cross planes. The additional plane just downstream of the casing recess shows results consistent with those seen in Fig. 5. In the midspan plane there is a band of high viscous entropy normal to the suction surface of the blade. This band does not intercept the pressure surface of the adjacent blade. Other views show that this band originates on the suction surface near the trailing edge, and not close to the location of minimum pressure.

Figure 7 shows relative total pressure distributions for the unshrouded and shrouded blade. The normalizing pressure, $P_{\mathrm{T} 1}$, is the inlet absolute total pressure. At midspan the loss in total pressure in the wakes and along the suction surface are clearly evident. Both configurations show that just downstream of the trailing edge there are regions of very 


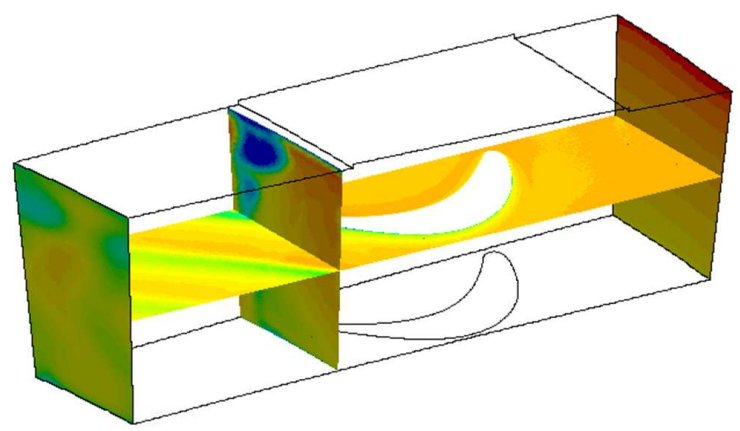

a) Unshrouded rotor

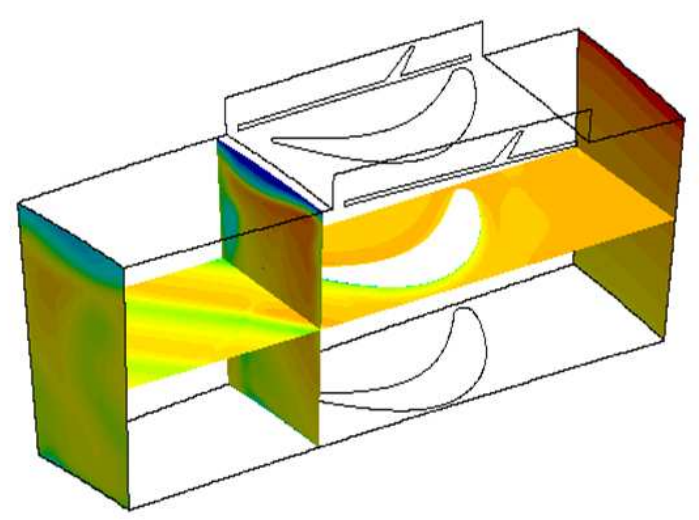

b) Shrouded rotor

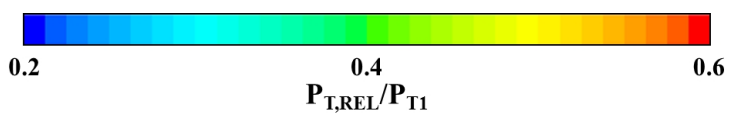

Figure 7. RELATIVE TOTAL PRESSURE.

low total pressure near the outer casing. The unshrouded case, Fig. 7a, shows the low pressure region extending further down the span, and to be on the suction side of the blade. The shrouded blade case, Fig. 7b, shows a thin low pressure region extending across the entire pitch. The total pressure at the inlet increases from hub to tip. This is the result of a non-uniform inlet absolute flow angle. The inlet flow angle is lower at the tip than at the hub.

\section{Blade Stress Analysis}

Figure 8 shows the rationale for shrouding CMC blades. The strength of HPT metallics(8,9), a CMC fiber material(10), and a single point for a woven CMC coupon(N24C)(11) are shown. The strength for the woven $\mathrm{N} 24 \mathrm{C}$ material is in the fiber direction. At a given temperature the 1000 hour strength in the fiber direction of a CMC exceeds that of either single crystal metal. The strength of the current single crystal metal continues to increase as the temperature decreases, but extensive cooling may be required to achieve further strength increases. For the $\mathrm{N} 24 \mathrm{C}$ CMC further temperature decreases result in only a small strength increase. The N24C CMC has a two-dimensional weave pattern, and is much weaker in the through thickness direction.

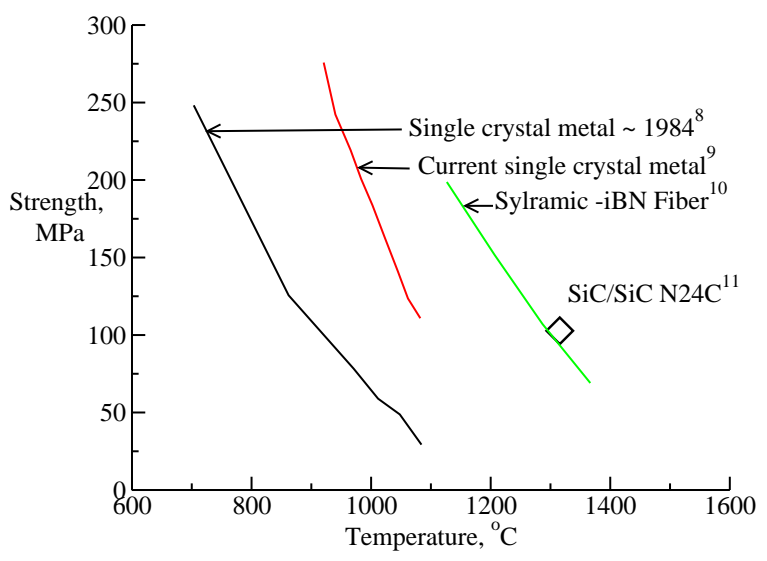

Figure 8. 1000 HOUR STRENGTGH VS. TEMPERATURE for DIFFERENT MATERIALS.

Static stress analysis was done, using ANSYS, for the blade coupled to a simplified root section. A series of cases will be examined. The stress reduction due to a lower density material is examined for a centrifugal load. The effect of different shroud geometries is examined for a centrifugal load. Stresses for a pressure load and for simultaneous pressure and centrifugal loads are examined for the unshrouded and shrouded blades. Thermal stresses are shown for a uniform temperature difference across the blade.

Material density effects. Stresses were calculated for a superalloy and a woven $\mathrm{SiC} / \mathrm{SiC} \mathrm{CMC}$ designated as N24A (DiCarlo et al.(11). The density of the superalloy is $8110 \mathrm{~kg} / \mathrm{m}^{3}\left(506 \mathrm{lb} / \mathrm{ft}^{3}\right)$, and the density of N24A is $2850 \mathrm{~kg} / \mathrm{m}^{3}\left(178 \mathrm{lb} / \mathrm{ft}^{3}\right)$. Young's Modulus for N24A is $22 \%$ greater than Young's Modulus for the superalloy, and Poisson's ratio for N24A is $48 \%$ of Poisson's ratio for the superalloy.

Turbine blade stresses were calculated for the engine operating speed,(rpm), of 21772 . Below the blade platform a simplified root section was used. The blade was constrained at the base of the root. The consequences of the boundary constraint was confined to a small area close to the base of the root. This work is focused on the relative change in stresses, and not on the absolute stress levels. Centrifugal stresses can be reduced by lowering engine speed. Pressure stresses decrease as the inlet total pressure decreases.

Figure 9 shows Von Mises stresses in $\mathrm{Pa}\left(\mathrm{N} / \mathrm{m}^{2}\right)$ for both materials. The maximum stress shown in Fig. 9a of $2120 \mathrm{MPa}$ corresponds to a stress of $307 \mathrm{ksi}$. High stresses close to this magnitude are confined to a very small region where the blade trailing edge intersects the hub platform. The areas where the stresses are above $706 \mathrm{MPa}(102.4 \mathrm{ksi})$, the yellow region, are very small. Near the blade hub there are small regions of high stress near the trailing edge and close to the leading edge. 


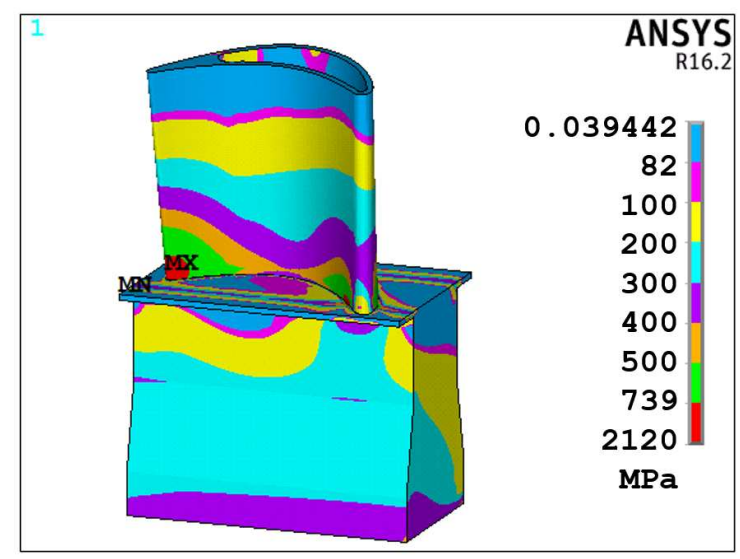

a) Superalloy material

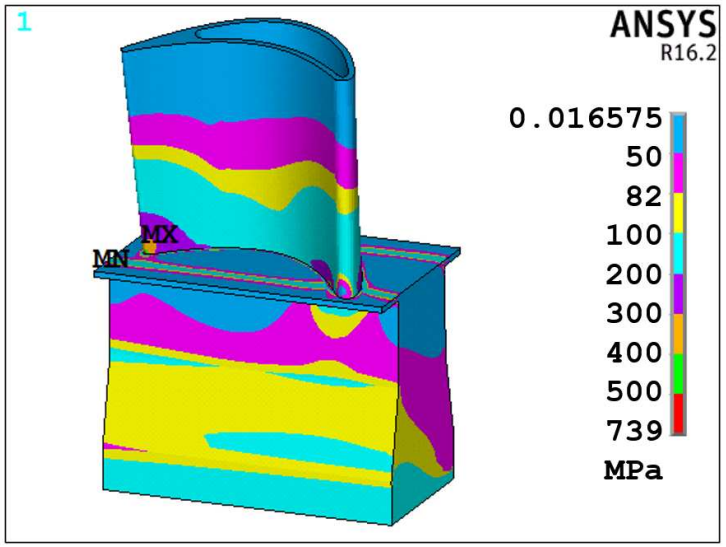

b) N24A Si/SiC CMC material

Figure 9. Von Mises STRESSES DUE to CENTRIFUGAL LOADS, $P a$.

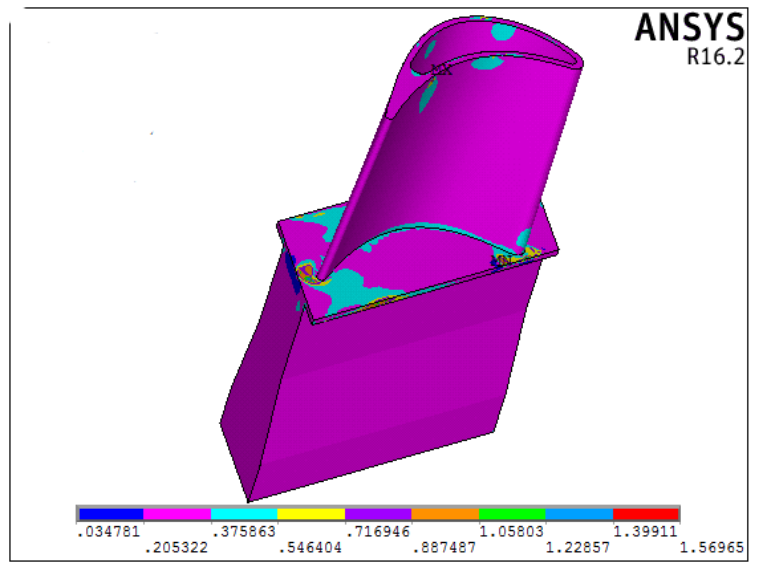

Figure 10. RATIO of N24-to-SUPERALLOY Von Mises STRESSES.

Figure 9b shows results for the N24A CMC material. Here the maximum Von Mises stress is
$739 \mathrm{MPa}(107 \mathrm{ksi})$. High stresses close to this value are again confined to a very small region where the blade trailing edge intersects the hub platform. The yellow region, where stresses exceed $246 M P a(35.7 k s i)$, is slightly smaller than the corresponding region in Fig. 9a. Figures 9a and 9b are similar, but the scales are different. The ratio of stresses where the purple and cyan regions meet, 164MPa-to-471 MPa closely matches the ratio of material densities, $2850 \mathrm{~kg} / \mathrm{m}^{3}$-to- $8110 \mathrm{~kg} / \mathrm{m}^{3}$.

Figure 10 shows the ratio of stresses for N24Ato-superalloy for the centrifugal load. Because fillets have not been incorporated in the model, stresses near the junction of the blade and hub platform are expected to be over predicted, and perhaps more importantly, unreliable. Away from the blade-hub junction, almost all regions have a ratio less than 0.376 , which is close to the density ratio of 0.35 . Higher stress ratios are seen on the hub platform and near the blade tip. Near the blade tip the actual stresses are low for both materials. Hub platform stresses away from the blade are also low, since there is no blade directly causing centrifugal loads for these higher than density ratio regions. There is no significant region where the ratio of stresses exceeds 0.55 .

Stresses for shrouded blade. Von Mises stresses were calculate for three shroud geometries. The first is a thin shroud, with the same thickness as shown in Fig. 2, $(0.76 \mathrm{~mm})$. The first shroud did not have the knife seal, but the second shroud geometry did. The second geometry was the shroud geometry used for the aerodynamic analysis. The third shroud geometry was similar to the first shroud, but the shroud thickness was five times greater, $(3.81 \mathrm{~mm})$. This thick shroud had a thickness that was $10 \%$ of the blade span, and did not have a knife seal.

Figure 11 shows three comparisons of Von Mises stresses for the shrouded and unshrouded blades. Two somewhat unexpected results are shown in these comparisons. The first is the very high stresses seen on the shroud itself. High stresses where the shroud and blade tip meet are not unexpected. However, the high stress region on the shroud is not confined to near the junction of the blade and shroud. The shroud results are in contrast with the hub platform results. Stresses are low for the hub platform even though the hub radius is $85 \%$ of the tip radius. While the high shroud stresses were not expected, they are not unprecedented. Cherry et al.(12) discuss the importance of having enough material in the shroud of LPT turbines to satisfy stress requirements. Porreca et al.(13) showed maximum stresses occurring on blade shroud configurations, rather than near the blade hub. 

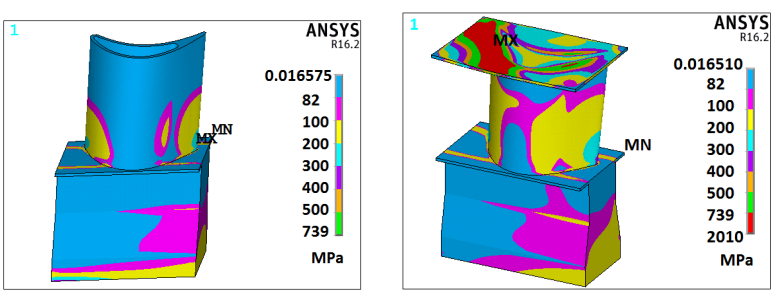

a) View of the suction surface
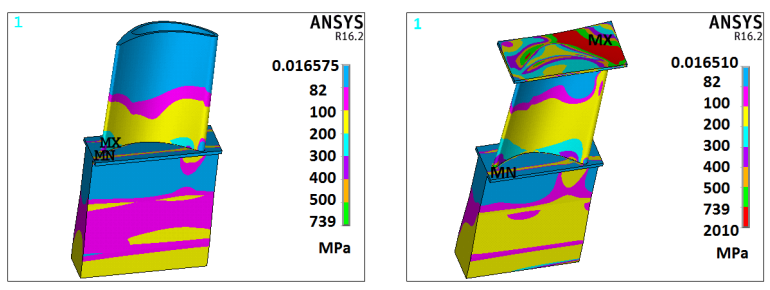

b) View of the pressure surface from top
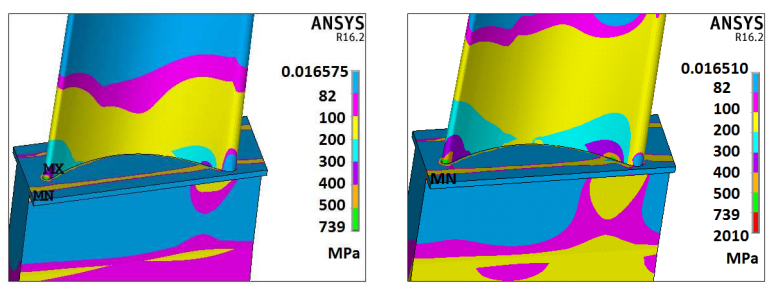

c) Close up of blade-hub region

Figure 11. Von Mises STRESSES for UNSHROUDED \& SHROUDED BLADES, N24A MATERIAL, $P a$.

The second somewhat unexpected result is that blade stresses do not dramatically increase when a shroud is present. This is significant in the relatively high stress region near where the blade and hub platform intersect. In contrast with the high stresses in the shroud, the mild increase in blade stresses shown in Fig. 11c, due to centrifugal loads, favors the possibility of using shrouded HPT rotor blades when the blades are made using CMC materials.

The very high stresses seen in the shroud, are unacceptable, and would be present whether the blade and shroud was made of a superalloy or CMC material.

Effect of knife seal on stress. It was hoped that the presence of the knife seal would significantly reduce shroud stresses. Figure 12 shows that this did not occur. There is a small increase in maximum shroud stresses due to the presence of the knife seal. However, the area with stresses above $500 \mathrm{MPa}(72.5 \mathrm{ksi})$ for the knife seal, Fig. 12, is similar to the area with stresses above $739 M P a(107 k s i)$ for the plain thin shroud, Fig. 11. Most published shrouded blade configurations show more than one knife seal. These result shows that in future work

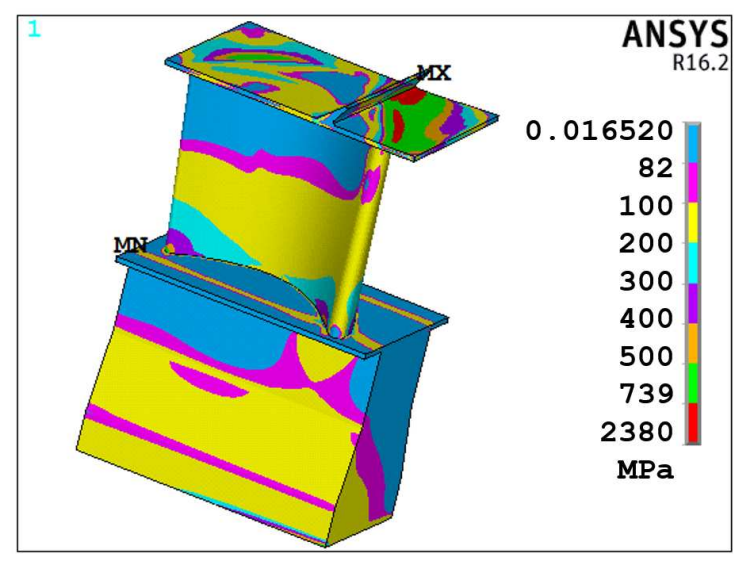

Figure 12. EFFECT of KNIFE SEAL on Von Mises STRESSES, $P a$.

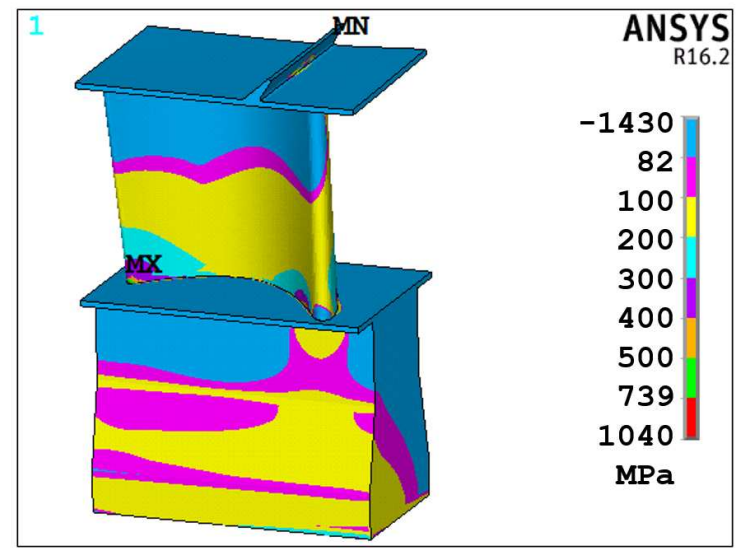

Figure 13. RADIAL STRESS DISTRIBUTION, $P a$.

shroud configurations with multiple knife seals should be analyzed to answer the question: "Do multiple knife seals result in acceptable shroud and blade stresses?"

Figures 12 and 13 shows that even though the Von Mises shroud stresses are excessive, the radial component of stress is low in the shroud. The Von Mises stresses account for stresses in all directions. The geometry indicates that the radial direction in the shroud will be the through thickness direction for woven $\mathrm{CMC}$ materials. In the blade itself the radial direction is aligned with a $\mathrm{CMC}$ fiber direction. Woven $\mathrm{CMC}$ are much weaker in the through thickness direction. Fortunately low radial shroud stresses, shown in Fig. 13, indicate that the shroud has sufficient through thickness strength. The similarity of stresses in the blade itself between figures 12 and 13 shows that blade stresses are in the radial direction. A SiC/SiC CMC rotor blade would have fibers aligned in the radial- high strength direction. 


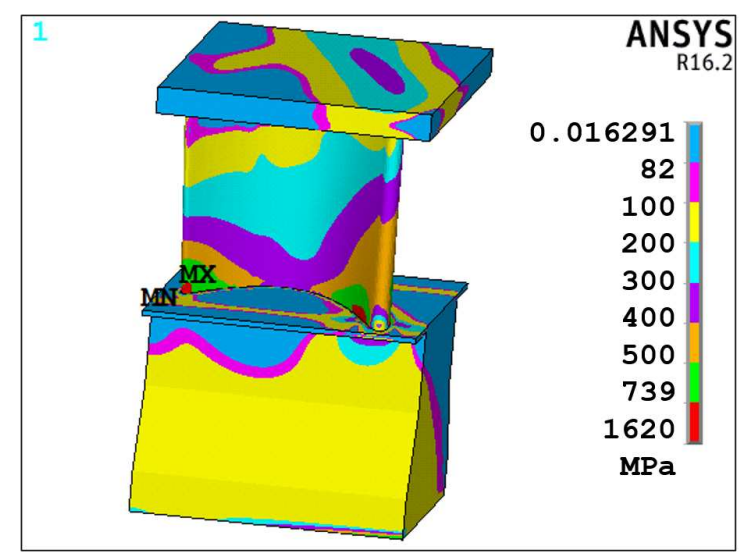

Figure 14. Von Mises STRESSES for THICK SOLID SHROUD, $P a$.

Effect of thick shroud. Figure 14 shows Von Mises stress distribution for a thick plain shroud. These results should be compared with those in Fig. 11. Figure 11 shows that the thin shroud had a significant area where stresses were greater than $739 M P a(107 k s i)$. This high CMC shroud stress is close to the blade hub region stress shown in Fig. 9a for the unshrouded superalloy blade. The superalloy blade hub region stress is above $706 \mathrm{MPa}(102 \mathrm{ksi})$. Comparing figures 11 and 14 shows that the high stress region in the shroud has been significantly reduced. The high stress region is not over $400 \mathrm{MPa}(58.0 \mathrm{ksi})$. The ratio of maximum shroud stress in the thin shroud, Fig. 11, to the maximum stress in the thick shroud, Fig. 14, approximately equals the inverse of the ratio of shroud thicknesses.

Unfortunately, with the thick shroud, high stresses are now seen near the hub of the blade. For the thick shroud there is a significant region where the stresses are above $500 M P a(72.5 k s i)$, and a smaller region where stresses are above $700 \mathrm{MPa}(101.5 \mathrm{ksi})$. The high stresses at the hub are caused by the thick shroud weighing $40 \%$ more than the hollow blade. Even so, the areas and magnitudes of high stress near the hub of the CMC blade with a thick shroud and the unshrouded superalloy blade, Fig. 9a, are similar at $\approx 700 M P a(101.5 k s i)$. What these results show is the importance of tailoring the shroud geometry to achieve structural and aerodynamic objectives. This conclusion is consistent with the conclusion of Cherry et al.(12) for a shrouded LPT blade. They showed that centrifugal stress at the blade tip was $20 \%$ of the centrifugal stress at the hub, and that shroud stresses nearly equaled stress at the blade hub.

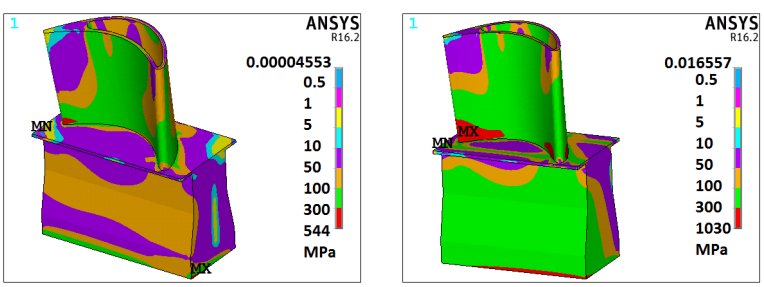

a) Pressure loads $\quad$ b) Pressure and Centrifugal loads

Figure 15. UNSHROUDED BLADE PRESSURE and COMBINED LOADS STRESS, $P a$.
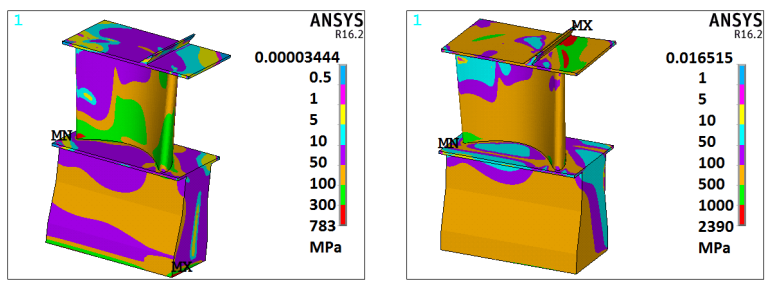

a) Pressure loads

b) Pressure and Centrifugal loads

Figure 16. SHROUDED BLADE PRESSURE \& CIMBINED LOADS STRESSES, $P a$.

Pressure loads Pressure stresses were calculated with an aggressive pressure distribution. The relative pressure distribution shown in Fig. 4 was applied at each spanwise location. The inlet relative total pressure was $50 \mathrm{~atm}$. The difference between the average stage inlet absolute total pressure and the average rotor inlet relative total pressure depends on the wheel speed. Even with a moderate wheel speed the HPT stage inlet absolute total pressure corresponding to a relative total pressure of 50atm. is expected to be over $60 \mathrm{~atm}$. Since HPT blades are hollow, pressure loads were calculated with an internal pressure of $50 \mathrm{~atm}$.

Figures $9 \mathrm{~b}$ and 15 show Von Mises stress distributions for the unshrouded rotor. Figure 9 is for centrifugal loads, and Fig. 15 shows stresses for pressure and combined loads. The high pressure load stresses, shown in Fig. 15a, that occur over a substantial portion of the blade are between $100 \mathrm{MPa}(14.5 \mathrm{ksi})$ and $300 \mathrm{MPa}(43.5 \mathrm{ksi})$. This is not much different than the range for high stresses shown in Fig. 9b for centrifugal loads. The range of high stresses for centrifugal loads is between $164 \mathrm{MPa}(23.8 \mathrm{ksi})$ and $246 \mathrm{MPa}(35.7 \mathrm{ksi})$. Comparing figures $9 \mathrm{~b}$ and 15 shows that combining pressure and centrifugal loads yields only a moderate increase in Von Mises stresses. 


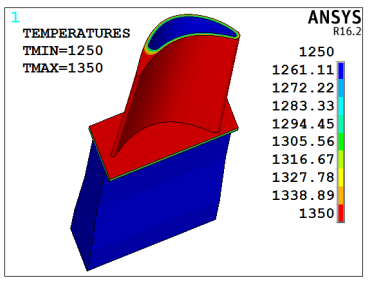

a) Unshrouded blade

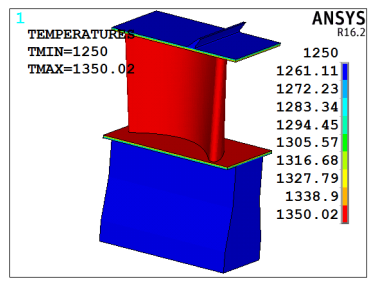

b) Shrouded blade
Figure 17. TEMPERATURES for UNSHROUDED \& SHROUDED BLADES, $K$.
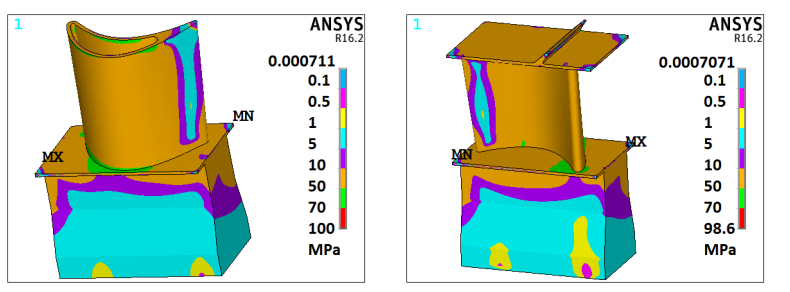

Figure 18. STRESSES DUE to $100 K$ TEMPERATURE GRADIENT, $P a$.

It is worth noting that Fig. 9a shows that single crystal superalloy blades have much higher centrifugal stresses than the pressure load stresses shown in Fig. 15a. While pressure stresses depend on material structural properties, the differences in these properties between the superalloy and N24A are much less than the difference in density. For current metallic blades centrifugal stresses are greater than pressure load stress, especially considering that current blades have inlet relative total pressures closer to $25 \mathrm{~atm}$. than to $50 \mathrm{~atm}$.

Figures 12 and 16 show the shrouded rotor blade stresses from individual loads and when pressure and centrifugal are combined. Stresses in the shroud due to pressure loads are much lower than stresses due to centrifugal loads. Even if shroud centrifugal load stresses were as low as for the thick shroud shown in Fig. 14, pressure load stresses would be lower than centrifugal load stresses. It is likely that in an "optimized" shroud geometry centrifugal load stresses would be between those shown in figures 12 and 14 .

Thermal load stresses Stresses were calculated for a uniform temperature difference across the walls of the blade. Surfaces not exposed to mainstream air were $100 \mathrm{~K}$ colder than surfaces exposed to the main flow air. This is illustrated in Fig. 17. Because of the uniform internal and external temperatures, temperature gradients, seen clearly in Fig. 17a, are also uniform around the blade. Cooling schemes can be designed to approach a uniform temperature gradient.
Figure 18 shows that thermal stresses are relatively low. Almost all stresses in the blade and shroud are below $50 \mathrm{MPa}(7.3 \mathrm{ksi})$. This does not mean that thermal stresses should be neglected. While the Von Mises stresses are low, thermal stresses, unlike centrifugal stresses, are not necessarily aligned with the CMC fiber directions. For blades cooled using film cooling additional thermal stresses can be expected. With film cooling the temperature difference across the blade is not uniform. Just downstream of a row of film cooling holes the temperature difference is small. Just upstream of the next row of cooling holes the temperature difference is much larger due to the lower film cooling effectiveness. Streamwise temperature gradients are likely to add additional stresses. Analysis for streamwise temperature gradients was not done because gradients depend on a specific engine applications.

\section{CONCLUSIONS}

This work showed that shrouding can significantly improve HPT stage aerodynamic efficiency, and highlighted the importance of designing a structurally sound light weight shroud for HPT turbine applications. A light weight shroud resulted in a $1.3 \%$ increase in blade row efficiency, and only small increases in stresses near the hub of the blade. However, the shroud itself had regions of very high stresses. On the other hand, a thick shroud had low stresses, but stresses near the blade hub substantially increased. The addition of a single knife seal to the light weight shroud reduced maximum shroud stresses. By one measure the decrease in Von Mises stresses was close to $30 \%$. While it did not sufficiently decrease the high shroud stresses, the presence of the knife seal resulted in only a small increase in blade stresses near the hub. Fortunately, while the thin shroud had high Von Mises stresses, stresses in the radial direction of the shroud were low. In a $\mathrm{SiC} / \mathrm{SiC} \mathrm{CMC}$ shroud, unlike a CMC blade, the radial direction is likely to be the through thickness direction. Typically, CMC materials have significantly less strength in the through thickness direction. There are strategies to mitigate against high stresses in the shroud. Multiple knife seals, which are common in shrouded LPT turbines, may reduce maximum stress in a thin shroud.

The predicted increase in HPT blade efficiency due to replacing an unshrouded HPT blade with a shrouded blade was $1.3 \%$ for a clearance equal to $2 \%$ of span. Walsh and Fletcher(14) show that a one percent increase in HPT stage efficiency improves SFC and thrust by up to two percent when the 
Bypass ratio is ten. The predicted increase in HPT stage efficiency was calculated using the Star$\mathrm{CCM}+\mathrm{CFD}$ analysis. For both the unshrouded and shrouded cases the analysis included flows between the blade or the moving shroud and the stationary casing.

Pressure loads assumed an average rotor inlet relative total pressure of $50 \mathrm{~atm}$. The average inlet relative total pressure to the first stage HPT rotor is only about $3 / 4$ of the compressor discharge absolute total pressure. This relative total pressure of $50 \mathrm{~atm}$. is higher than in current engines, but is relevant to future higher OPR engines. Even though centrifugal stresses were low because of the low material density, and the inlet pressure was conservatively high, the maximum pressure stress was lower than the maximum centrifugal stress. On the other hand, nearly equal areas of high stress were seen for centrifugal and pressure loads. These areas were not at the same locations. There was a relatively small increase in maximum stress when pressure and centrifugal loads were applied simultaneously.

Thermal stress were calculated for a $100^{\circ} \mathrm{C}$ temperature difference across the blade walls. These stresses were low compared to centrifugal stresses.

\section{Acknowledgement}

This work was supported by the NASA Phase I SBIR contract NNX16CC31P. Vikram Shyam was the technical monitor for this work.

\section{REFERENCES}

1. Yoon,S., Curtis, E., Denton, J., and Longley, J., 2014, "The Effect of Clearance on Shrouded and Unshrouded Turbines at Two Levels of Reaction," ASME J. of Turbomachinery, Vol. 136, No. 2, 021013

2. Moffitt, T.P., Szanca, E.M., Whitney, W.J., and Behning, F.P., 1980, "Design and Cold-Air Test of Single-Stage Uncooled Core Turbine With High Work Output," NASA TP 1680.

3. Jones, S., personal communication

4. Kanjirakkad, V., Thomas, R., Hodson, H., Janke, E., Haselbach, F., and Whitney C., 2008, "Passive Shroud Cooling Concepts for HP Turbines: Experimental Investigations," ASME J. of Turbomachinery, Vol. 130, No. 1, 011017

5. Lin, G., Kusterer, K., Ayed, A.H., Bohn, D., and Sugimoto, T., 2014, "Conjugate Heat Transfer Analysis of Convection-cooled Turbine Vanes Using $\gamma-\operatorname{Re}_{\theta}$ Transition Model," Int. J. of Gas Turbine, Propulsion and Power Systems, December 2014, Vol. 6, No 3, pp. 9-15.
6. Ameri, A.A., Steinthorsson, E., Rigby, D.L., 1998, Effects of Tip Clearance and Casing Recess on Heat Transfer and Stage Efficiency in Axial Turbines, NASA CR-1998-208514.

7. Haas, J. E., and Kofskey, M.G., 1979, "Effect of Rotor Tip Clearance and Configuration on Overall Performance of a 12.77-Centimeter Tip Diameter Axial-Flow Turbine," NASA TM 79025, AVRADCOM 78-54.

8. Mattingly, J.D, , 1996, "Elements of Gas Turbine Propulsion," McGraw-Hill Inc. NY.

9. Dever, J.A., Nathal, M.V., and DiCarlo, J.A., 2013, "Research on High Temperature Aerospace Materials at NASA Glenn Research Center, J. of Aerospace Engineering, Vol. 26, pp 500-514.

10. DiCarlo, J.A., 2013, "Advances in $\mathrm{SiC} / \mathrm{SiC}$ Composites for Aero-Propulsion," NASA TM-2013217889

11. DiCarlo, J.A., Yun, H.-M., Morscher, G,N., and Bhatt, R.T., 2005, "SiC/SiC Composites for $1200^{\circ}$ and Above," in Handbook of Ceramic Composites, ed. Bansal, N.P., pp 27-98, Kluwer Academic Publisher, New York, NY

12. Cherry, D.G., Gay, C.H., Lenahan, D.T., 1982, "Low Pressure Turbine Test Hardware Detailed Design Report", NASA CR-167956.

13. Porreca, L., Kalfas, A.I., and Abhari, R.S., 2009, "Aerothermal Analysis of a Partially Shrouded Axial Turbine," AIAA Journal of Propulsion and Power, Vol. 25, No. 1, pp. 181-190.

14. Walsh, P.P., and Fletcher, P., Gas Turbine Performance, $2^{\text {nd }}$ edition, 2004, Co-published by Blackwell Science Ltd, and ASME Press, p. 337. 